\title{
An Analytical Study of Nifty 50 and Financial Sector Indices
}

\author{
Dr. Bhuvaneshwari $\mathrm{D}^{1}$ \\ $\left\{\right.$ db.hum@psgtech.ac.in $\left.{ }^{1}\right\}$ \\ Assistant Professor, Department of Humanities, PSG College of Technology, Coimbatore - 641004 , \\ India. ${ }^{1}$
}

\begin{abstract}
The present study analyses the movements of 'Nifty 50' and the Nifty financial sector indices owing to their significance in the economy. The OLS regression, Granger Causality, and Impulse Response Function were estimated to measure the changes in the future responses of 'Nifty 50 ' to the changes in the select financial sector indices for the period April 2019 to March 2021. The findings indicated the direction of causality between the indices. Further, the study also provides evidence for the existence of a significant response on the Nifty 50 due to the changes in the financial sector indices in India..
\end{abstract}

Keywords: Nifty 50, Nifty Financial Sector Indices, Granger Causality, Impulse Response Function.

\section{Introduction}

The financial sector of India that includes the banking, non-banking financial companies, and the insurance industry is highly influential in the real economy since they create credit and mobilize savings. This forms the basis for investments, provides payment and fund transfer services to boost businesses and consumers; thereby creating avenues of growth in the economy. The performance of the financial sector is crucial to the sustained functioning of the markets and risk mitigation. The financial sector that operates through the equity markets has increased access to capital flows, but the pandemic has had its impact on the indices of this sector as well globally and India in specific.

According to Business Standard, Apr 2020, expected a 16-22 percent fall in Nifty, the leading benchmark index of the National Stock Exchange (NSE) of India. The fear of many businesses turning to bankruptcy, increased NPA, liquidity depletion in the financial services sector, and termination of capital flows have alarmed the policymakers to estimate the extent of the impact of 2020 pandemic shutdowns on the various sectors of the economy. This study is therefore an attempt to assess the movements in the 'Nifty 50' and Nifty sectoral indices with specific reference to the financial sector indices owing to their significance in the economy. 


\section{Review of Literature}

The studies conducted earlier on stock market indices have pointed out the volatility using various models like GARCH, impulse response function, and the causality analysis using various sectoral indices and comparatively for markets. Some of the significant studies in line with the present study carried out during the pandemic for the Indian context are presented in this section.

Florence, Dibin and Victor (2020) determined the underlying linkages and correlations among eight sectoral indices National Stock Exchange (NSE) using a Granger causality test under the VAR environment for the period 2009 - 2018. The study found that an efficient portfolio would consist of 50\% stocks from pharma and media as defensive stocks and 50\% from the rest of the six sectors as cyclical stocks. Raval and Mehta (2020) examined the Nifty 50 associated with financial services and the pharmaceutical sector for the period 2008 to 2018. The study found a strong positive correlation Nifty 50 has with financial services as well as with the pharmaceutical sector by applying simple correlation and independent t-test.

Singh and Kumar (2020) analyzed the pattern of the Nifty 50 and sectoral indices and the findings indicated that among the major indices of India, the financial service sector outperformed all the other indices. A similar study by Pandey, Samanta, and Kumar (2017) for the period 2011 - 2015, using correlation and multiple regression analysis, revealed that Nifty 50 and the select sectoral indices had a significant causal relationship except for Nifty Realty and the Nifty Bank sector.

Mohanty, Satpathy and Mohapatra (2019) determined the performance of the Sensex sectoral indices and found a significant relationship between the indices using correlation coefficient. AnjanaRaju and Velip (2019) examined the correlation among 11 Nifty indices of 9 Emerging markets of Asia for the period 2009 - 2018 and results showed the existence of a positive correlation among the Nifty sectoral indices in the markets.

This current study will add to the literature and enables further understanding of the various financial sector indices of Indian stock markets and help to learn changes in the behavior of the indices following the economic conditions.

\section{Objectives}

The objectives of this study are

1. To estimate the causality between 'Nifty50' and select financial sector indices.

2. To measure the changes in the future responses of 'Nifty50' to the changes in the select financial sector indices.

Data

The financial sector forms the fulcrum of any economy and India is no exception. The sector includes the banking, NBFC, and the insurance sector which are connected to the lives of the people regularly. Considering this significant role, it is essential to measure this sector and the indices operated in the BSE and NSE, which will facilitate policymakers, investors, and governments to forecast and make strategic decisions to meet the impact. Hence the present study has considered the sectors Banks, Financial Services, Private Banks and PSU Banks of India. The indices of these sectors are used as variables of the study and they are N50 for Nifty 50; NB representing Nifty Bank; NFS for Nifty Financial Services; NPB for Nifty Private Banks and NPSUB for Nifty Public Sector Banks. The daily closing prices of the 
select financial sector indices were drawn from the NSE website for two years April 2019 to March 2021.

\section{Methodology}

The Augmented Dickey-Fuller (ADF) and the Phillips and Perron (PP) tests were used to check for the presence of unit root among the variables. The Normal Least Square Regression was estimated to derive the coefficients, which was further used to predict the responses of the stock indices. The causal relationship was examined using the Granger Causality test and the Impulse Response Function (IRF) graphs were plotted to identify the presence of shocks in the system.

\section{Empirical Results and Discussion}

a. Summary Statistics

The summary statistics of the variables of the study period are presented in Table 1.

Table 1 Summary Statistics

\begin{tabular}{|l|l|l|l|l|l|}
\hline Particulars & N50 & NB & NFS & NPB & NPSUB \\
\hline Mean & 11753.66 & 27697.05 & 12856.05 & 15252.16 & 2079.28 \\
\hline Median & 11669.15 & 29395.95 & 12995.50 & 16321.60 & 2155.90 \\
\hline Maximum & 15314.70 & 37306.25 & 17504.90 & 19866.55 & 3425.10 \\
\hline Minimum & 7610.25 & 16917.65 & 8298.50 & 8974.30 & 1087.20 \\
\hline Std Deviation & 1531.12 & 4846.69 & 1999.60 & 2668.23 & 653.81 \\
\hline Skewness & 0.27 & -0.43 & -0.06 & -0.60 & 0.26 \\
\hline Kurtosis & 3.33 & 2.10 & 2.38 & 2.06 & 1.86 \\
\hline Jarque-Bera & 8.22 & 31.85 & 8.22 & 47.79 & 32.63 \\
\hline Probability & $0.02^{* *}$ & $0.00^{* *}$ & $0.02^{* *}$ & $0.00^{* *}$ & $0.00^{* *}$ \\
\hline Observations & 495 & 495 & 495 & 495 & 495 \\
\hline *** Significant at the5\% level & & & & \\
\hline
\end{tabular}

There exists a significant difference between the minimum and maximum values of the select variables, indicating the volatile nature of the movements of the variables. Among the select stock indices, 'Nifty 50' and NPSUB were right-skewed (positive skewness), whereas NB, NFS and NPB were found to be left-skewed (negative skewness). The kurtosis coefficient values for NB, NFS, NPB and NPSUB were positive and less than 3, indicating a platykurtic distribution. The Jarque-Bera test statistics and its probability imply that all the study variables were not normally distributed. 


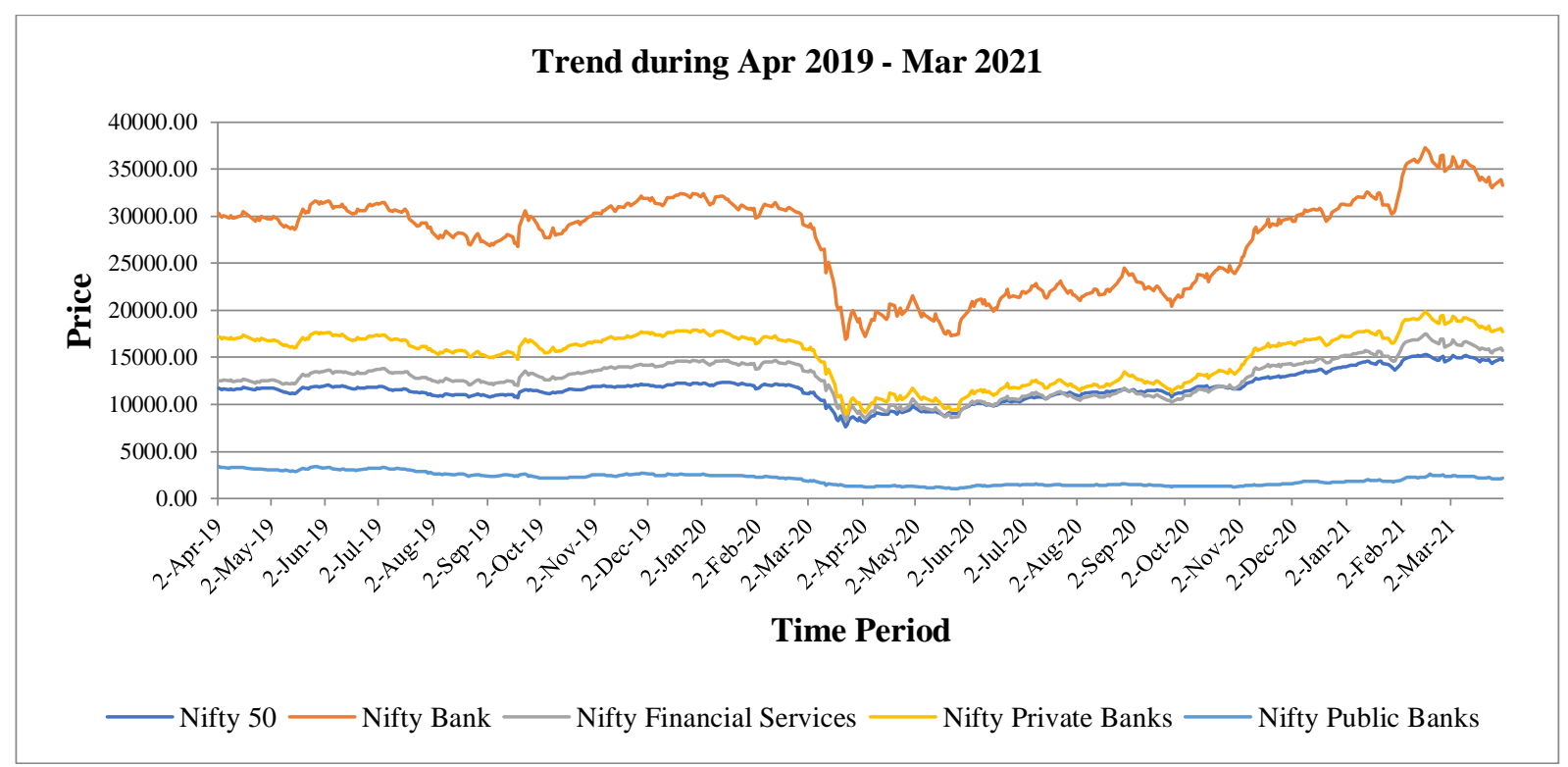

\section{Figure 1 Graphical Representation on the Prices of the Select Financial Sector Indices}

b. Testing the Data for Stationarity

The results of unit root tests for checking the stationarity of the data are presented in Table 2.

Table 2 Results of Unit Root Tests

\begin{tabular}{|l|l|l|l|l|}
\hline \multirow{2}{*}{ Time Series Data } & ADF values & PP values \\
\cline { 2 - 5 } & Level & $\begin{array}{l}\text { First } \\
\text { Difference }\end{array}$ & Level & $\begin{array}{l}\text { First } \\
\text { Difference }\end{array}$ \\
\hline N50 & -1.14 & $-23.03^{* *}$ & -1.26 & $-23.07^{* *}$ \\
\hline NB & -0.93 & $-21.24^{* *}$ & -1.14 & $-21.35^{* *}$ \\
\hline NFS & -1.12 & $-21.61^{* *}$ & -1.28 & $-21.69^{* *}$ \\
\hline NPB & -1.03 & $-20.99^{* *}$ & -1.20 & $-21.06^{* *}$ \\
\hline NPSUB & -0.80 & $-21.67^{* *}$ & -0.89 & $-21.68^{* *}$ \\
\hline${ }^{* *}$ Significant at the5\% level & & & \\
\hline
\end{tabular}

The stationarity test indicated the presence of unit root for all the variables at the 'level' and was found to be integrated of order 1.

$$
\text { c. Time Series Regression }
$$

In this study, the time series regression method is applied to predict the responses of Nifty 50 based on the response history of the select financial sector indices.

Table 3 Estimation of Time Series Regression Model

\begin{tabular}{|l|l|l|l|l|l|l|}
\hline Independent Variables & Coefficient & Std. Error & T & R Square & $\begin{array}{l}\text { Adjusted } \\
\text { R Square }\end{array}$ & F \\
\hline Constant & 3.77 & 2.72 & $1.39^{* *}$ & & & \\
\cline { 1 - 4 } NB & -0.16 & 0.06 & $-2.76^{* *}$ & 0.87 & 0.87 & \multirow{2}{*}{806.10} \\
\hline NFS & 0.62 & 0.05 & $11.60^{* *}$ & & & \\
\hline
\end{tabular}




\begin{tabular}{|l|l|l|l|l|l|l|}
\hline NPB & 0.25 & 0.08 & $3.15^{* *}$ & & & \\
\cline { 1 - 4 } NPSUB & 0.42 & 0.09 & 4.66 & & & \\
\hline${ }^{* *}$ Significant at the5\% level \\
\hline
\end{tabular}

The tests of regression analysis presented in Table 3 provide information on how changes in the select financial sector indices (independent variable) impact the N50 (dependent variable). The $R^{2}$ value is 0.87 (above 0.60 ) which indicates that the model is fit. Therefore, it can be inferred that the select financial sector indices could explain 87 percent of the variability of 'Nifty 50'stock index price movements. The adjusted $R^{2}$ value is observed to be in line with the $R^{2}$ value and identified that the select financial sector indices well explains the movements of 'Nifty 50' and no changes can be observed in the model when the addition of independent variable is studied. The large $\mathrm{F}$ value i.e., 806.10 is statistically significant and confirms the joint effect of all the study variables.

\section{d. Causality Test}

Granger causality test was used to determine the causality between the N50 and the select financial sector indices.

Table 4 Values of F statistic using Granger Causality Test

\begin{tabular}{|l|l|l|l|}
\hline Null Hypotheses & F-Statistic & Probability & Result \\
\hline NB does not Granger Cause N50 & 2.25 & 0.11 & Accept \\
\hline N50 does not Granger Cause NB & 3.11 & $0.04^{* *}$ & Reject \\
\hline NFS does not Granger Cause N50 & 3.18 & $0.04^{* *}$ & Reject \\
\hline N50 does not Granger Cause NFS & 4.05 & $0.02^{* *}$ & Reject \\
\hline NPB does not Granger Cause N50 & 2.17 & 0.12 & Accept \\
\hline N50 does not Granger Cause NPB & 3.33 & $0.04^{* *}$ & Reject \\
\hline NPSUB does not Granger Cause N50 & 0.18 & 0.83 & Accept \\
\hline N50 does not Granger Cause NPSUB & 1.61 & 0.20 & Accept \\
\hline${ }^{* *}$ 5\% level of significance & & & \\
\hline
\end{tabular}

The results of the Granger causality in Table 4 revealed that there was a significant causal relationship between $\mathrm{N} 50$ and the select financial sector indices in the short-run. A unidirectional causality existed from N50 to NB and NPB, implying a change in the 'Nifty 50' index had a significant impact on the 'Nifty Bank' and 'Nifty Private Banks' index prices. It was further found that there existed bidirectional causality between N50 and NFS.

e. Impulse Response Function (IRF)

IRF graphs were plotted to identify the presence of shocks due to the variables that will impact the future values of the endogenous variable in the system. The responses of the 'Nifty 50 ' due to the shock on the select financial sector indices are presented in Figure 2. 


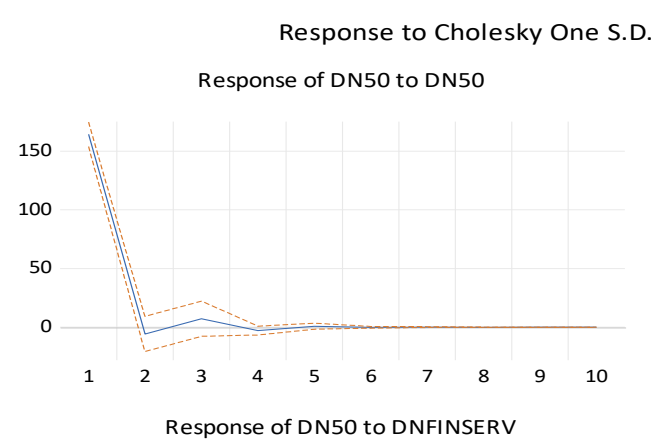

(d.f. adjusted) Innovations \pm 2 S.E.

Response of DN50 to DNFINSERV

Response of DN50 to DNBANK
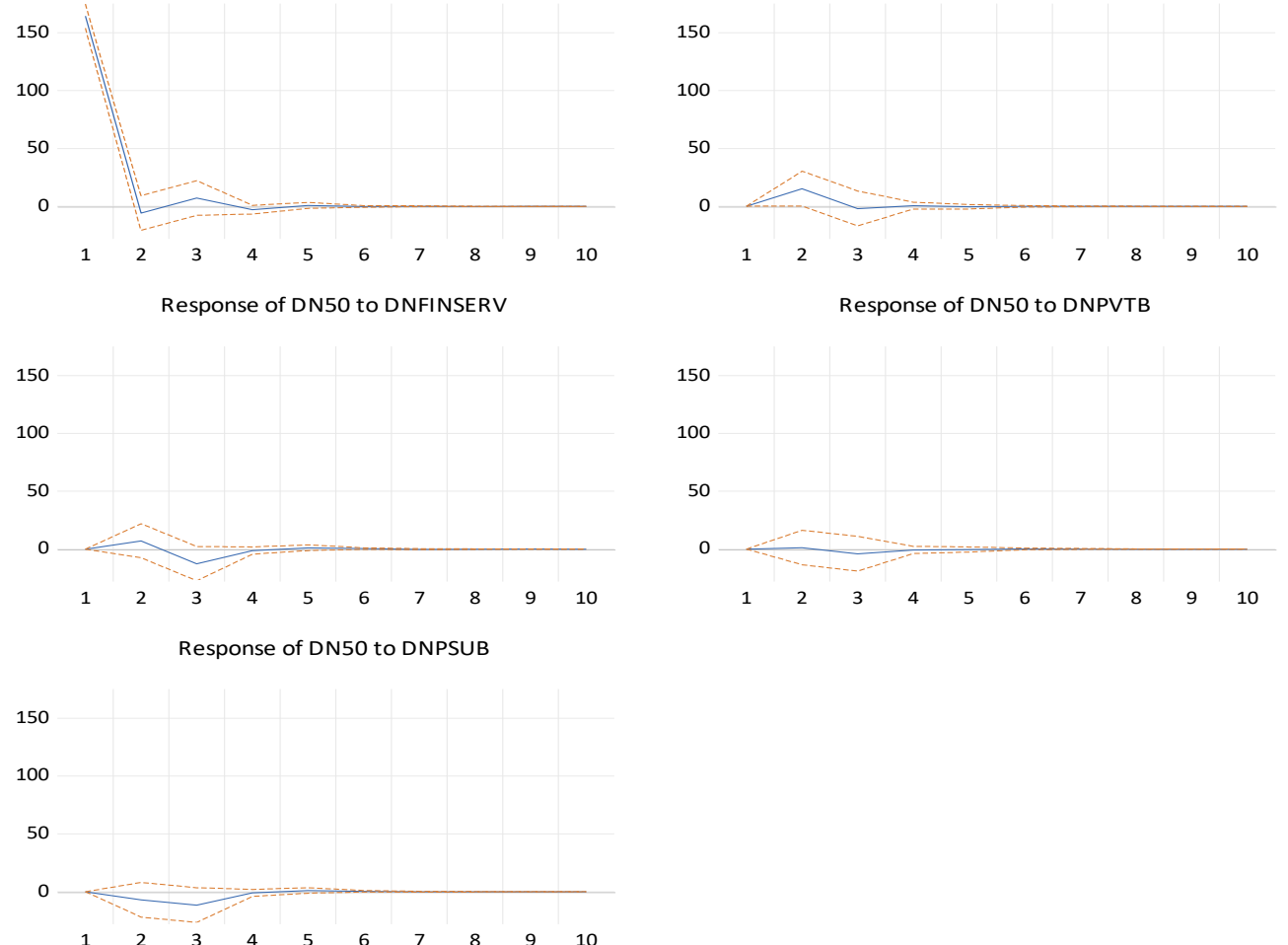



IRF plots show the response of N50 to the changes in NB, NFS, NPB and PSUB, indicating significant responses. The empirical analysis carried out using the regression, Granger causality, and IRF provides evidence to suggest that there exists a significant response on the 'Nifty 50' due to the changes in the financial sector indices in India. 


\section{Conclusion}

The stock markets across the globe move on the spectrum of volatility caused by information asymmetry shock experienced at various timeframes and government policy decisions. The assessment of the volatility in the performance of the stock market parameters is considered vital by investors and policymakers to enable forecasting and decision making. This study was carried out to examine empirically the movements of 'Nifty 50 ' and the financial sector indices of the NSE in India, using robust econometric techniques. The results indicated that the financial sector indices via; NB, NFS, NPB and NPSUB experienced volatility, with the volatility being highest for the NSE Banks. A unidirectional causality existed from 'Nifty 50' to 'Nifty Bank' and 'Nifty Private Banks'. It was further found that there existed bidirectional causality between 'Nifty 50' and 'Nifty Financial Services'. The IRF plots also suggest that there exists a significant response on the 'Nifty 50 ' due to the changes in the movements of financial sector indices in India. This study would help the policymakers and the investors by providing useful information for decision-making concerning 'Nifty 50' and Nifty financial sector indices.

\section{References}

[1] Singh, K., \& Kumar, V. (2020). Dynamic linkage between nifty-fifty and sectorial indices of national stock exchange. American Journal of Economics and Business Management, 3(2), 17-27.

[2] Pandey, S., Samanta, A., \& Kumar, D. (2017). An empirical study on relationship of nifty \&sectoral indices of National Stock Exchange. The Indian Journal of Commerce, 70(1), 70-78.

[3] Mohanty, D., Satpathy, M., \& Mohaptra, S. R. (2019) Impact of sectoral indices' fluctuation on SENSEX. International Journal of Recent Technology and Engineering. 8(4), 2603-2608.

[4] AnjanaRaju, G., \& Velip, S. P. (2019). Causality relationship between Indian NSE Nifty sectoral indices and Asian emerging stock markets: An empirical study. Ajanta Prakashan. 8(1), 1-10.

[5] Florence, M. A., Dibin, K. K., \& Victor, V. (2020). Sectoral Correlations and Interlinkages: NSE. SCMS Journal of Indian Management, 17(3), 94-102.

[6] Raval, N., \& Mehta, R. (2020). A comparative study between nifty50 with financial services \& pharmaceutical sector. International Journal for Innovative Research in Multidisciplinary Field. 6(5), 286-291.

[7] Secondary Data on NSE Stock Indies. Retrieved from https://www1.nseindia.com/products/content/equities/indices/historical_index_data.htm. NSE. 